DOI https://doi.org/10.36059/978-966-397-104-9/75-95

\title{
GEOINFORMATION SYSTEMS
}

\section{Kyselov V. B.}

\section{INTRODUCTION}

Globalization and internationalization of the economy, the destruction of trade barriers between a large number of countries in Europe and Asia, the widespread use of IT and IS in the activities of government and commercial entities, the emergence and rapid development of the global Internet led to the emergence of IS in the mid-1980s., which allowed the organization of On Line mode of work of multinational corporations located on different continents. Distances have ceased to be an obstacle to the efficient operation of distributed companies, providing virtually instant communication and delivering information to analyze and make a business decision, implementing the well-known $7 \times 24$ principle (7 days a week, 24 hours a day) ${ }^{1}$.

Much of this information is available in almost every field of activity in the form of drawings, maps, plans, diagrams and explanatory texts. These could be gas or oil pipelines from Siberia to Western Europe, submarines and combat patrols along borders, circuits on a country or subway scale across the city, building plans or interconnections between company offices, environmental monitoring map territories, atlas of land cadastre or map of natural resources, etc.

Choosing a location for a company affiliate abroad, marketing and recruiting in another country, coordinating the "binding" of production to the area where it is most advantageous from the point of view of the most efficient use of resources in most cases ceased to be a difficult task.

There was an urgent need to present geographic and related information in a convenient graphical form, combining several sheets of map image on the monitor screen.

The rapid development of specialized systems and technologies, known as Geographical Information Systems (GIS), enabled the successful completion of such tasks by the end of the twentieth century.

\footnotetext{
${ }^{1}$ Марк Спортак, Френк Паппас и др- Компьютерные сети и сетевые технологии. PlatinumEdition: Пер. сангл. Санкт-Питербург.: ООО «ДиаСофтЮП», 2005. 720 с.
} 
GIS technologies are widespread and used in science, technology, and business. Time-bound objects are used in geodesy, cartography, geology, navigation. Processing and consolidation into a single system of photographic images from space for scientific and military purposes, processing of data of geophysics and geodynamics, use in the national economy (compilation of urban, regional and federal land cadastres) and many other things are done with the use of GIS technologies. Numerous definitions of "Geoinformation system" and "geoinformation technology" reflect the multifaceted nature of the concepts.

Table 1

GIS definitions chronology

\begin{tabular}{|c|c|c|}
\hline Author & Definition of GIS & Source \\
\hline 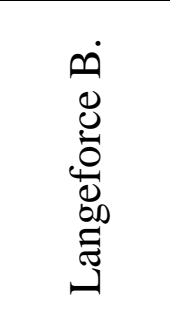 & $\begin{array}{l}\text { A system that includes } \\
\text { components for collecting, } \\
\text { transmitting, storing, processing } \\
\text { and issuing territorial information. }\end{array}$ & $\begin{array}{l}\text { Theoretical Analysis of } \\
\text { Information Systems. Lund, } 1966 .\end{array}$ \\
\hline 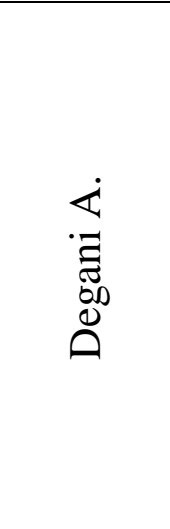 & $\begin{array}{l}\text { Dynamically organized set of data } \\
\text { (dynamic database) connected to a } \\
\text { set of models implemented on a } \\
\text { computer for the computational, } \\
\text { graphic and mapping of this data } \\
\text { into spatial information in order to } \\
\text { meet the specific needs of certain } \\
\text { users within the structure of well- } \\
\text { defined concepts and technologies } \\
\text {. }\end{array}$ & $\begin{array}{l}\text { Methodological observation on the } \\
\text { state of geo cartographic analysis } \\
\text { in the context of automated spatial } \\
\text { information systems. - Map Data } \\
\text { Process. - Proc. NATO Adv. } \\
\text { Study Inst. Maratea, June 18-29, } \\
\text { 1979, Acad. Press. } \\
\text { 1980x 207-220. }\end{array}$ \\
\hline 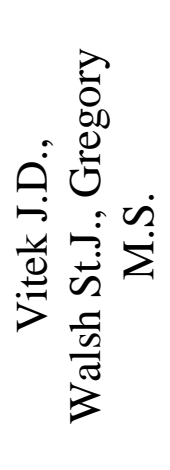 & $\begin{array}{l}\text { An information system that can } \\
\text { provide input, manipulation and } \\
\text { analysis of geographically defined } \\
\text { data to support decision making. }\end{array}$ & $\begin{array}{l}\text { Accuracy in geographic } \\
\text { information systems: an } \\
\text { assessment of inherent and } \\
\text { operational errors. - Record } \\
\text { 9th Symp. Spat. Technol. Remote } \\
\text { Sens. Today and Tomorrow. } \\
\text { Sioux Falls, S.D., 2-4 Oct. } 1984 . \\
\text { [нечеткое совпадение] - Proc. } \\
\text { Silver Spring, 1984, pp. 296-302. }\end{array}$ \\
\hline
\end{tabular}


Table 1 (continuance)

\begin{tabular}{|c|c|c|}
\hline Author & Definition of GIS & Source \\
\hline 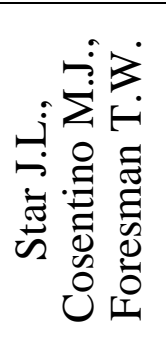 & $\begin{array}{l}\text { Spatially defined system for } \\
\text { collecting, storing, searching and } \\
\text { manipulating data, as well as a } \\
\text { means of analyzing and managing } \\
\text { this data. }\end{array}$ & $\begin{array}{l}\text { Geographic information systems: } \\
\text { question to ask before it's to } \\
\text { late. - Machine Processing of } \\
\text { Remotely ended Data with Special } \\
\text { emphasis on Thematic Mapping } \\
\text { Data and Geographic Information } \\
\text { Systems, 1984, pp. 194-197. }\end{array}$ \\
\hline 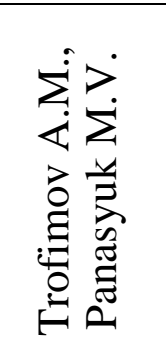 & $\begin{array}{l}\text { Implemented with the help of } \\
\text { automatic means (DEC) repository } \\
\text { of the system of knowledge about } \\
\text { the territorial aspect of the } \\
\text { interaction of nature and society, } \\
\text { as well as software that simulates } \\
\text { the functions of search, input, etc. }\end{array}$ & $\begin{array}{l}\text { Geoinformation systems and } \\
\text { problems of environmental } \\
\text { management. Kazan, pub. house } \\
\text { of Kazan University, 1984, } \\
142 \text { pp. }\end{array}$ \\
\hline 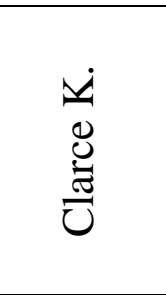 & $\begin{array}{l}\text { A special case of an information } \\
\text { system where a database consists } \\
\text { of observations of spatially } \\
\text { distributed phenomena, processes, } \\
\text { or events that can be defined as } \\
\text { points, lines, and contours. }\end{array}$ & $\begin{array}{l}\text { Geographic information systems: } \\
\text { definitions and prospects. - Bull. } \\
\text { Geogr. and Map Div. Spec. Libr. } \\
\text { Assoc., 1985, № } 142 \text {, pp. } 12-17 .\end{array}$ \\
\hline 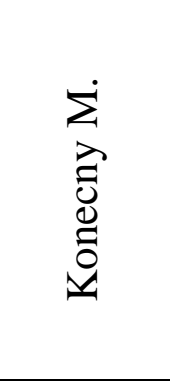 & $\begin{array}{l}\text { A system consisting of humans, as } \\
\text { well as the technical and } \\
\text { organizational means that collect, } \\
\text { transmit, enter and process data } \\
\text { for the production of information } \\
\text { that is convenient for later use in } \\
\text { geographical research and for its } \\
\text { practical application. }\end{array}$ & $\begin{array}{l}\text { Geograficke informacni } \\
\text { systemy. - Folia prirodoved. fak. } \\
\text { UJEP v Brne, 1985, t. 26, № 13, } \\
196 \text { s. }\end{array}$ \\
\hline 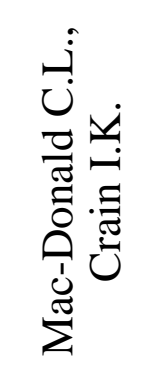 & $\begin{array}{l}\text { A system that is implemented to } \\
\text { collect, store, manipulate, search } \\
\text { and display specific geographical } \\
\text { data. }\end{array}$ & $\begin{array}{l}\text { Applied computer graphics in a } \\
\text { geographic information system: } \\
\text { problems and successes. - } \\
\text { Computer graphics and app, 1985, } \\
\text { vol. [нечеткое совпадение] } \\
\text { 1980x 34-39. }\end{array}$ \\
\hline 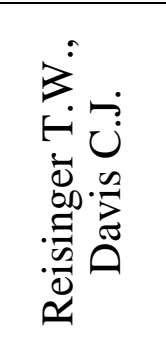 & $\begin{array}{l}\text { A system that manipulates and } \\
\text { manages data stored in the form of } \\
\text { thematic layers, geographically } \\
\text { defined relative to the map base. }\end{array}$ & $\begin{array}{l}\text { A map-based decision support } \\
\text { system for operational planning of } \\
\text { timber harvests. - Winter Meet. } \\
\text { Amer. Soc. Arg. Eng., Ayatt } \\
\text { Regency, Chicago, Decem ber } \\
\text { 17-20, 1985. Paper N 1604. - } \\
\text { St. Joseph: ASAE, 1985, } 12 \text { p. }\end{array}$ \\
\hline
\end{tabular}


Table 1 (continuance)

\begin{tabular}{|c|c|c|}
\hline$\frac{\dot{\alpha}}{\dot{\vec{\omega}}}$ & $\begin{array}{l}\text { A complex of hardware and } \\
\text { software and human activities for } \\
\text { storing, manipulating and } \\
\text { displaying geographically } \\
\text { (spatially correlated) data. }\end{array}$ & $\begin{array}{l}\text { The National Science Foundation } \\
\text { National Center for Geographic } \\
\text { Information and Analysis - } \\
\text { International Journal of } \\
\text { Geographical Information } \\
\text { Systems, 1987, v. 1, № 4, } \\
\text { pp. 302-306. }\end{array}$ \\
\hline$\stackrel{\dot{E}}{\vec{D}}$ & $\begin{array}{l}\text { Internally positioned automated } \\
\text { spatial information system } \\
\text { designed to manage and map data. }\end{array}$ & $\begin{array}{l}\text { Fundamental operations in } \\
\text { computer-assisted map analysis - } \\
\text { International Journal of } \\
\text { Geographical Information } \\
\text { Systems, 1987, v. 1, № 4, } \\
\text { pp. 119-136. }\end{array}$ \\
\hline 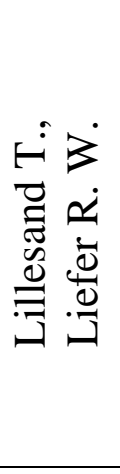 & $\begin{array}{l}\text { A system that includes a database, } \\
\text { hardware, specialized } \\
\text { mathematical software, and } \\
\text { software packages to expand the } \\
\text { database, manipulate data, } \\
\text { visualize them in the form of maps } \\
\text { or tables, and ultimately make } \\
\text { decisions about a particular } \\
\text { business activity }\end{array}$ & $\begin{array}{l}\text { Remote session and image } \\
\text { interpretation. N.Y., John Willey } \\
\text { and Sons, 1987, } 722 \text { p. } \\
\end{array}$ \\
\hline 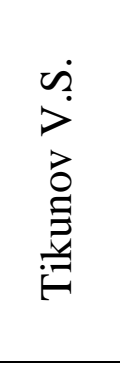 & $\begin{array}{l}\text { Interactive systems capable of } \\
\text { realizing the collection, } \\
\text { systematization, storage, } \\
\text { processing, evaluation and means } \\
\text { of obtaining new information and } \\
\text { knowledge about spatial-temporal } \\
\text { phenomena on their basis. }\end{array}$ & $\begin{array}{l}\text { Modern means of research of the } \\
\text { system "social and industrial } \\
\text { environment". - Izvestiya } \\
\text { Vsesojuzn. Geograf. obshestva, } \\
\text { 1989. 121p. 4, p. 299-306". }\end{array}$ \\
\hline 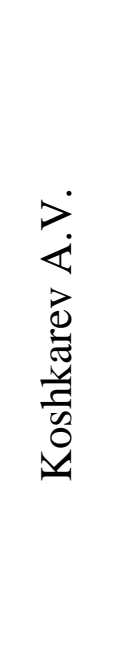 & $\begin{array}{l}\text { A hardware-software human- } \\
\text { machine complex that provides the } \\
\text { collection, processing, display and } \\
\text { dissemination of spatial- } \\
\text { coordinated data, integration of } \\
\text { data and knowledge about } \\
\text { territories for their effective use in } \\
\text { solving scientific and applied } \\
\text { geographic problems related to } \\
\text { inventory, analysis, modeling, } \\
\text { forecasting and management of } \\
\text { the environment and territorial } \\
\text { organization of the company. }\end{array}$ & $\begin{array}{l}\text { Cartography and geoinformatics: } \\
\text { ways of interaction. Izv. } \\
\text { AN USSR, geographic series, } \\
\text { 1990, № 1, p. } 32 \text {. }\end{array}$ \\
\hline
\end{tabular}


Table 1 (ending)

\begin{tabular}{|c|c|c|}
\hline 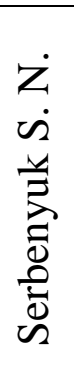 & $\begin{array}{l}\text { Scientific and technical complexes } \\
\text { of automated collection, } \\
\text { systematization, processing and } \\
\text { presentation (delivery) of } \\
\text { geographic information in a new } \\
\text { quality with the condition of } \\
\text { increasing knowledge about the } \\
\text { study of spatial systems. }\end{array}$ & $\begin{array}{l}\text { Cartography and geoinformatics - } \\
\text { their interaction. M., 1990, 159p. }\end{array}$ \\
\hline 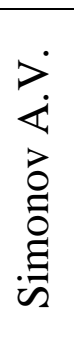 & $\begin{array}{l}\text { A system of hardware and } \\
\text { algorithmic procedures designed } \\
\text { for digital support, replenishment, } \\
\text { control, manipulation, analysis, } \\
\text { mathematical and cartographic } \\
\text { modeling and figurative display of } \\
\text { geographically coordinated data. }\end{array}$ & $\begin{array}{l}\text { Agroecological cartography. - } \\
\text { Chisinau, publishing house } \\
\text { "Stiinets", } 1991 \text { - } 127 \text { p. }\end{array}$ \\
\hline
\end{tabular}

By analyzing these definitions and omitting repetitions, you can identify the main keywords of GIS technologies. These are "information system", "geographical information", "software-hardware", "interactive systems", "mathematical static and dynamic models", "spatial-coordinated data", "control, analysis, data manipulation", "visualization of data in the form of maps or tables","thematic map layers","mapping databases".

And finally, let's give the definition of 1997, taken from GOST (State Standard), which largely integrates the above definitions and uses almost all of the above keywords.

"Geographic Information System (GIS) is a set of technical, software, communication and information tools that provide input, processing, storage, mathematical and cartographic modeling and imaginative integrated representation (visualization) of spatial and related attribute data to solve problems of territorial planning and Management (OST HSE 02.001-97).

Thus, GIS technologies are, first and foremost, computer technologies and systems that allow to work effectively with dynamic data on spatialdistributed objects, supplementing their clarity of representation and ability to build models and solve problems of spatio-temporal analysis.

GIS, like any information system, is equipped with data collection and processing tools, allows you to accumulate and analyze such information, quickly find and process the necessary geographical information and display them in a user-friendly way. 
The use of GIS technologies can dramatically increase the efficiency and quality of work with spatial-distributed information in comparison with traditional "paper" cartographic methods.

Geographic Spatial Distributed Data means information that identifies the geographical location and properties of natural or artificially created objects, as well as their boundaries on earth, above and below ground, on water, above and under water, in outer space. This information can be obtained through remote sensing, mapping and various types of imagery, including space photography.

The data contains four integrated components: the location and spatial relationships of the objects, the time at which these components are fixed, and the rate of change of the specified parameters. In other words, geographical data describes:

- the geographical spatial position of physical or simulated objects is represented by 2-dimensional ( $\mathrm{X}, \mathrm{Y}$ coordinates on the plane), 3-dimensional (latitude, longitude, height above the level of the geoid) and 4-dimensional coordinates (latitude, longitude, height above geoid level, time in seconds) in the coordinate system assigned to the middle pole of the Earth and the position of the middle equator;

- the properties of objects or models may contain information that does not explicitly indicate spatial orientation and is descriptive, however, such information is important and is also included in geographic data;

- spatial relations determine the relative location of objects or models, for example, the position of object $\mathrm{A}$ with respect to object $\mathrm{B}$ on a plane, in space or in time, the motion of $A$ relative to $B$, the nesting of $A$ in $\mathrm{B}$ and so on;

- time parameters can characterize both the relationship of objects (models) and the life cycle of geographical data.

Areas of GIS are extremely diverse today: land management, resource control, ecology, municipal government, transport, economics, social tasks and more.

The first work on GIS technology began more than 25 years ago in Canada and the United States, where it was originally used primarily for land management in the southern and western United States and the mapping of Canadian areas of the Arctic by computer processing of satellite photographs. 
Nowadays, GISs of mass use are becoming more widely used - for general electronic plans of cities, plans for the development of mineral deposits and offshore oil exploration, engineering communications schemes, transport traffic schemes, etc.

It is estimated that up to $80-90 \%$ of the information we usually deal with can be presented as GIS for various purposes. To support critical areas of activity - nuclear power, oil and gas extraction and transportation, disaster relief, and defense activities - specialized Web resources are now being increasingly developed and deployed to implement distributed GIS and GIS portals. The development of such portals is now carried out on the basis of international standards, created by well-known international organizations for standardization - ISO (International Organization for Standardization) and OGC (Open Geospatial Consortium). These are standards such as ISO 19115 Meta Data, ISO 19139 Meta Data - XML Schema Implementation, Catalog Interfaces, Geography Markup Language and Web Map Service.

GIS is currently one of the fastest growing segments of the market for high-tech computing with a large number of large firms. These include: Intergraph (http://www.intergraph.com/gis), ESRI (http://www.esri.com), MapInfo (http://www. mapinfo.com), Autodesk (http: //www.autodesk.com), CalComp, Space Imaging (http://www.geoeye.com) and many others.

Non-professional users have high-quality Web resources, such as GoogleMap (http://maps.google.com) and Geography NetWork (http://www.geographynetwork.com).

\section{GIS Classification}

A variety of existing GIS technologies fit into different types of classifications.

GISs differ in the subject area of information modeling - Urban GIS (UGIS), Environmental (GIS), Manufacturing FacilitiesGIS - (MFGIS) and so on.

The problematic orientation of GIS is determined by the scientific and applied tasks it solves - inventory of resources, analysis, evaluation, monitoring, management and planning, decision support.

Integrated GIS (IGIS) combines the functionality of GIS and digital imaging systems (remote sensing data) in a single integrated environment. 
Multiscale GIS (MSGIS) is based on multiple representations of spatial objects, providing graphical or cartographic reproduction of data at any zoom level based on the data set that provides the largest spatial resolution.

Spatio-temporal GIS (STGIS) operates with spatial-temporal data. Implementation of geoinformation projects (GISProject) includes the usual life cycle stages:

- Feasibility Study, including the study of user requirements and functionality of GIS software used;

- technical and economic feasibility study for a GIS development;

- Costs/Benefits;

- GIS Designing, including the GIS Pilot Project stage;

- GIS Development;

- testing in a small territorial fragment or test area;

- Prototyping;

- GIS Implementation;

- Setting Into Operation.

Scientific, technical, technological and applied aspects of the design, creation and use of GIS are the subject of study of the branch of rapidly developing informatics - geoinformatics.

In the history of GIS development, geoinformatics identifies four main periods:

- 60's - mid 70's - exploration of the principal possibilities of using large computers of that time for the accumulation, processing, analysis and construction of banks and geographic databases; theoretical work in the field of analysis and construction of banks and geographic databases; theoretical work in the field of processing such data, accumulation of experience;

- mid 70's - mid 80's - the emergence of automated control systems (ACS), including the first specialized GIS, the development of large state GIS projects in the field of control of nuclear energy and hydropower, defense, etc.;

- mid 80's - late 90's - the emergence of the concept of GIS, the emergence of a market for software that implements various GIS based on personal computers, powerful servers and network communications; expanding the scope of GIS based on integrated databases and powerful 
DBMS, including tools for processing and necessary visualization of geographical and descriptive data;

- the emergence of application GIS for non-professional users, as well as specialized distributed GIS, such that support state and corporate databases of such data;

- the beginning of the twentieth century - today - increased need for geographical data in connection with the globalization of many sectors of the economy, strong competition in the GIS market, the emergence of large groups of users interested in specific application software GIS-tools, the use of artificial intelligence and intellectual networks in GIS design, application of mobile agent software technology for gathering specialized information in expert GIS, formation of world GIS infrastructure.

These stages of development showed all new requirements for the functionality of different GIS, but these requirements were outlined in the third stage in the 80's - 90's. Let's note at once that GIS is not just a geographical map, transferred to a computer.

Geoinformation systems store information in the form of sets of thematic electronic layers, which can be combined by any necessary attribute. Therefore, GIS technologies integrate operations to work with layers, databases, analysis tools and layer virtualization that contain the right data in the right combinations.

For example, building a large supermarket in a metropolitan area requires a common data analysis. The transformation (merging, splitting, scaling, and so on) of layers and conversion of data from one format to another is done by methods of mathematical mapping and data management in the GIS database.

\section{GIS functionality}

In GIS, there are five basic functional procedures with data: input, manipulation, control, query and analysis, visualization.

Geographic data (numbers, text, images) for use in GIS are entered in vector or bitmap format, if such data already exists in the appropriate digital format, or pre-digitized using a digitizer or scanner. Each element or object in the image has a coordinate binding. Thus, any properties and characteristics of real objects (models) or their elements are "tied" to the location of the object in the coordinate grid. It should always be borne in mind that digitization or data entry technologies in a specific thematic 
layer, as well as overlay and erection of layers, can be accompanied by significant errors, which will further lead to significant mapping of the mapping data and visualization of the result.

Manipulators are various ways of highlighting, grouping and converting data, such as bringing all geoinformation to a single scale and projecting it onto a specific thematic layer for ease of co-processing.

For storing, structuring and managing GIS data, relational databases with elements of OLAP technologies (On Line Analytical Processing) and report generation technologies (Report Creation) are most commonly used. Query and analysis can be performed at different levels of complexity from the simplest questions of "where an object is and what its descriptive properties" to searching and compiling data on complex templates and "And what if ..." scenarios.

Modern GIS has advanced means of analyzing the proximity and overlay of objects belonging to different thematic layers. The first tool is related to the allocation of buffer zones around specified objects by a combination of different parameters (for example, "Select settlements located not more than two kilometers from a specific airport" or "Calculate the areas of damage in the event of an accident at the NPP and select settlements that fall into these zones"). The second allows you to calculate the intersection, merging, exclusion and other combinations of two or more distributed objects (overlay operations) in the construction of layers.

The results of various operations can be simply displayed on the screen or create (draw) new objects with any set of attribute characteristics. Advanced visualization tools and methods allow GIS to easily control the display of data. The traditional result of processing, analyzing and displaying spatial geographic data is a map, supplemented by accounting documents, embossed color images of real and simulated objects, photographs, tables, diagrams, video clips of the situation development and other multimedia tools.

In addition to these basic operations, modern GIS have a number of special groups of functions that implement user-defined tasks: finding the optimal route, finding the shortest distances, calculating spatial statistics, creating models of geological structures, marine and air currents, etc.

Electronic maps and thematic descriptions are used to graphically represent geographical data describing real objects and their models in GIS. Parameters of location of objects and their relations are spatial 
(metric) data, parameters of temporal and thematic properties - attribute (descriptive) information.

The GIS data model is based on the map object classifier. It defines the composition and content of metric, semantic, thematic, dynamic properties of the object and their visual means. The system of symbols is formed using the palette of colors, the texture of lines and fillings, character templates and fonts.

In modern GIS, the technology of layered graphical representation of information is implemented, it corresponds to the representation of coordinate models in topological form (representation of objects and their relations in the form of a graph). Attribute information is displayed on the electronic map layer by numbers, symbols and their sets - inscriptions. Coordinate and attribute data are established in the database via the appropriate identifiers (default or user interface).

Bitmaps and vector models are used to represent geographic features.

A raster model is a representation of land and oceans as a discrete set of elements that make up the desired picture. These elements are called Pixels (Picture Element), and they display an electronic map themed layer on the monitor screen.

Each pixel occupies some small area in the form of a rectangle, has the coordinates of the center $(\mathrm{X}, \mathrm{Y})$ in the plane of the map layer associated with the coordinates of the points of the geographical object, and the description of its properties (brightness, color and tone density), corresponding to similar properties of the object.

Bitmap digital images can be obtained directly by digitally photographing the Earth's surface from satellites, or when processing aerial photos by digital scanning methods using digitizers.

Such images are good for visual perception and are convenient for multidimensional processing. However, they take up a lot of space in the memory of computing devices and are poorly scaled - with multiple and multiple zooms, compression and decryption, image clarity is greatly impaired. Therefore, in those cases where the need to scale images without loss of clarity is pre-determined, vector graphics technology is used.

A vector model is a structurally defined graphic representation of a spatial object. The position of the points of the object is given by the coordinates of the end of the vector $(\mathrm{x}, \mathrm{y}, \mathrm{z})$ and a description of the properties of this point. The mapping of an object is given by a set of 
vectors. Since the end of the vector (point) has no area, there is no distortion when the image is zoomed in or out multiple times (scaled). Vector graphics operate with point, line (arcs and contours) and surface (polygon) models of spatial objects.

The following forms of vector data model are valid:

- whole-polygonal structure (topological structure of "spaghetti" type);

- linear nodal (graph structure);

- relational (structure of relations);

- irregular triangulation network.

The formation of the topology is to determine the position of points and nodes in the selected coordinate system on a plane or in space (for relief images) and the digital coding of relationships between point, line and area geographic objects.

Currently, object-oriented geographic database models (such as ESRI's ArcGIS), object forming classes, relationship classes, geometric networks, and layered topologies are being used.

\section{GIS Implementation and Support Tools}

GIS can be divided into four broad functional categories:

- simple map and charting tools;

- desktop computer and embedded GIS packages;

- full-featured systems;

- Enterprise-wide GIS (corporate systems).

\section{Data Diagramming and Mapping Tools}

The tools in this category are cheap and easy to use, but with some functionality, they can be fully mapped to more complex systems. Typical examples are spreadsheet tools, such as Microsoft Map in Excel and Lotus Maps. These applications are accessible to any user of MS Excel spreadsheets and Lotus Notes and make it easy to use thematic mapping features - displaying map information from their database on the map. Any manager in ten minutes will learn how to make the cards needed to prepare a business decision.

Another simple but quite functional tool is Business Map. It is designed for users who need more than just thematic mapping. Business Map works with the data of the most popular spreadsheets and databases and supports 
such business and management analysis capabilities as, for example, spatial queries, display map composition, identifying and linking coordinates, zip codes and real address information of objects. This category also includes Viewer Facilities. For example, you can cite Geomedia Viewer from Intergraph or a free ArcExplorer that allows you to view and request ArcInfo, ArcView and SDE data, including over the Internet.

An important factor limiting the widespread use of more complex GIS in business tasks is the relative complexity of studying software. To address this obstacle, advanced interfaces have been developed that give the average user powerful and comprehensible geographical analysis tools.

\section{Desktop computers and embedded GIS packages}

In the first half of the 1990s, the growth of GIS sales was largely driven by the demand for desktop and embedded GIS. And if the first Desktop Mapping systems had limited geographic data capabilities, then modern GISs, "delivered" to a personal computer or embedded in other software, offer a complete set of tools for data analysis and management. These products include: ArcView, Maplnfo, GeoMedia, GeoGraph/GeoDraw, which have advanced DBMS functionality and provide tools for analyzing, integrating and displaying geographic data ${ }^{2}$.

For example, an ArcView software package can be used to bind spatial data (via GPS or GLONASS satellite positioning), import data from other sources (mapping and government or corporate databases), and perform complex statistical and modeling studies, to build variants of scenarios of situation development, to carry out on-line processing of field data obtained during geodetic surveys of terrain with laser theodolites.

Let's take a brief look at two of the most typical GISs in this class ArcView and MapInfo.

ArcView has the tools to select, view and edit a variety of geographic data, create layouts and map templates with legends, graphs and charts, digitize maps using a scanner, associate map objects with attribute information in HotLink mode (with image archives obtained multimedia tools), address coding, printing of cartographic materials. ArcView works directly with many data formats, provides access to standard DBMS (Ingres, Sybase, Oracle, Informix), reads DXF and DWG file formats, and includes

${ }^{2}$ Фролов А.В., Фролов Г.В. Глобальные сети компьютеров: Практическое введение в Internet, E-mail, FTP, WWW и HTML, программирование для WindiwsSockets. Москва: Диалог. Москва: МИФИ, 1996. 283 c. 
the following features: invoking remote RPC (Unix) procedures, connection to other applications via DDE (Windows), connecting applications to VisualBasic. There are also a number of standard ArcView applications for engineering research, GPS SAPR3 interoperability, Internet submission.

MapInfoProfessional (http: //www.esti - map.ru) is now one of the real GIS leaders in digital mapping. In addition to the traditional features for a DBMS of this type, MapInfo allows you to collect, store, display, edit and process mapping data based on the spatial and temporal relationships of objects.

Data in different formats can be used in one session at a time.

Data sources can be:

- tables of own MapInfo databases;

- data in CAD vector formats (for embedded GIS applications) and various geoinformation systems: AutoCAD (DXF, DWG), Intergraph/MicroStationDesign, ESRIShape, ARC/INFOExport;

- bitmaps in GIF, JPEG, TIFF, PCX, BMP, PSD, ECW, BIL and GRID (GRA, GRD) formats;

- data obtained by GPS, GLONASS, electronic geodetic instruments (laser theodolites and rangefinders);

- Excel files, Access BASE, Lotus 1-2-3, and text files that, in addition to attribute (descriptive) information, can store the geographic coordinates of point objects.

MapInfo GIS can serve as a "mapping client" when working with common DBMSs such as Oracle and DB2, as it supports an effective mechanism for interacting with them through ODBC.

Moreover, access to data from Oracle DBMS is also possible through the internal interface (OCI) of this database.

MapInfo has a "geographical" extension of the built-in SQL query language, which allows you to organize samples based on the spatial relationships of objects - the distribution, nesting, overlapping, the intersection of object areas. Database queries can be saved as templates for later use.

MapInfo also has the ability to search and map objects by coordinates, address or system of different installed indexes. Windows Application Interaction allows you to integrate MapInfo's Maps window into Delphi, VisualBasic, C.

Sharing MapInfo and the MapBasic development environment enables each user to create specific applications to solve specific application tasks. 


\section{Full-featured systems}

Full-featured software products originate from major government projects of the 60s and 70s that were implemented on major Mainframe computers. They were used mainly by emerging analysts and experts in geoinformatics and were a tool to support unique and specialized research. Such GIS could be used only by qualified specialists who are competent both in software, in the principles of geography, and in problems of a specific application area.

Today, the state of things has changed - modern GIS tools are implementing geoinformatics methods using powerful software and hardware: open-access geographic Web servers, complex multi-factor spatial analysis tools, devices for generating the most accurate electronic, and preparing high-quality paper maps.

Full-featured GIS contain a complete set of geospatial processing tools, including data collection, integration, storage, automatic processing, editing, creation and maintenance of topology, spatial analysis, database connection, visualization and hard copies of any mapping information. The system runs on both WindowsNT and RISC - Unix workstations. In addition to the basic set ArcInfo contains a number of modules that extend the ability to handle location data in different applications.

\section{Corporate Systems}

Corporate GIS is typically distributed IS with client-server jobs. Enterprise GIS can be implemented using Spatial Database Engine (SDE) spatial data servers that work with ArcView and ArcInfo desktop applications. Such GISs allow you to operate huge amounts of geographic and attribute data and deliver this data to any user on a local or global network. In addition, because spatial data servers are typically implemented in standard relational databases, they are migrated to most database environments. Thus, tools like SDE can be used to:

- build high-speed GIS applications;

- integrate sophisticated geographical data processing features into application programs;

- deliver applications on a range of software and hardware platforms;

- increase the availability of geographical and attribute data and the ability to process and interpret it for business decisions; 
- integrate geographic data management into existing enterprise database management systems.

Such applications are most important for companies managing large infrastructures or utilities (such as energy networks), working in transportation and transportation, or developing natural resources - leading oil and gas companies everywhere use GIS to manage exploration, production, and resource allocation.

Corporate-type GIS is closely linked to a number of other types of information systems - Computer Aided Design (CAD), Enterprise Resource Planning (ERP), Logisticand Supply Chain Management (LSCM). Its main difference is the ability to collect, process, manipulate spatial data and perform qualified analysis.

The geographic information system GRASS - Geographic Resources AnalysisSupport System, freely distributed under the GNU Public License, has gained widespread popularity. In the current version, GRASS is a modular multifunctional geoinformation system of universal application.

The primary interface of GRASS to the Unix system is imprinted on the system interface, and the solution can be described as a combination of command and window interfaces. Moreover, the general concept of the interface is guessed in versions under different platforms.

In addition to the standard GUI, different GUI shells can be used, such as the widely known QGIS shell for the GRASS kernel. There is also a Java version of GRASS-JAVAGRASS, which provides a unique crossplatform. All this has ensured the success and wide spread of this geoinformation system.

\section{Related technologies: GIS, GPS and GLONASS}

GIS database management systems are designed to store and manage all types of data, including geographical (spatial) data. These data are most often obtained by methods of spatial remote sensing - measurements of the coordinates of objects on the Earth's surface using laser rangefinders at Earth observation points and reflectors on board artificial satellites of the Earth (ASE).

Global positioning system receivers and other Doppler radiometers are also used. These devices collect data in the form of sets of coordinates or images (mostly digital) and provide extensive processing, analysis and visualization of the data obtained. Development of the NAVSTAR GPS 
(NAVigation Satellite Timing And Ranging Global Positioning System) concept began in 1973 at the initiative of the US Department of Defense. The latest at that time navigation systems at the time, the Loran-C and Omega terrestrial systems, and the Transit satellite have ceased to meet the requirements of accuracy, independence from weather, round-the-clock operation and coverage.

In February 1978, the first experimental GPS satellite was launched. By mid-1993, there were already 24 satellites in orbit, which was enough to ensure continuous navigation anywhere on Earth. The final commissioning of the system was announced only in July 1995.

The GPS system consists of three parts: space, ground and user equipment.

The space part is 24 satellites moving in six orbits. The inclination of the orbits to the Earth's equator is 55 degrees, the angle between the orbital planes is 60 degrees. The orbit height is $20180 \mathrm{~km}$, the circulation period is 12 hours. 50W Satellite Transmitter Power If one of them fails, the others are able to fill gaps in the system, moving in orbit.

An important element of the satellite is an atomic clock, rubidium and cesium, four each, which set the on-board timeline. These scales are constantly in sync with the terrestrial precision time standards.

Each satellite is identified by a Pseudo Random Number (PRN) displayed on the GPS receiver. The terrestrial part consists of 4 surveillance stations located on the tropical islands. They track visible satellites and transmit data to the Command and Control Station at the Colorado Springs Air Force Base for processing on complex orbital software models called ephemeris. The data are transmitted back to the satellites through the ground stations and then transmitted by the satellite to the GPS receivers.

The custom portion includes a satellite receiver, a decoder and a program module for calculating the coordinates of the object on which the receiver is located. The accuracy of coordinate determination depends on many factors - the accuracy of the transmitting and receiving devices, the onboard and terrestrial time scales, the state of the ionosphere and troposphere, solar activity, humidity and pressure in the atmosphere, the geometry of the satellites in the field of view of the receiving antenna. By measuring the distances (pseudorange) of r1 and r2 by long-range or radiometric methods for several satellites, and 
comparing them with satellite surveying methods, it is possible to obtain the coordinates of ground-based tracking points and corrections to satellite orbital elements.

Satellite geometry is measured by the PDP (Position Dilution Of Precision) factor. The ideal location of the satellites corresponds to $\mathrm{PDP}=1$, the large values indicate poor satellite geometry. The PDP value is used as a factor for other errors when comparing observations.

Each pseudorange measured by the receiver has its own error, dependent on atmospheric interference, errors in ephemeris, reflected signal, etc. So, if the estimated values of these errors in the sum are about 50 meters and PDOP $=1.5$, then the expected error in determining the location will be 75 meters. If the receiver "caught" four satellites, and they are all close to the zenith of the observation site, then such satellite geometry is "bad" and the result error will be 90-150 meters. With the same 4 satellites, accuracy is much higher if they are spaced evenly along the horizon at an altitude of 20 to 50 degrees. In this case, the accuracy reaches 30 meters, which is about 1 second of the arc - which is already good accuracy.

Modern stationary GPSs provide accurate positioning of up to several fractions of a second when processing spatial data in GIS and precision of distance determination - up to several millimeters. It is clear that such precision is required for scientific and defense applications.

Aeronautical and marine GPS, installed on aircraft and ships, provide accuracy of up to 1 meter, for non-professional use is now quite a few meters accuracy.

Such GPS devices are mounted in mobile phones, in car navigation systems, etc. The final error of the \{GPS - GIS - electronic map\} will depend on the accuracy of each element of the system. It will be worth mentioning that coordinate map systems - such as, for example, Map Datum - are associated with different terrestrial ellipsoid models used in map construction in different countries. The difference between them can be up to $500 \mathrm{~m}$. When working with GPS and an electronic map, the user must take this into account and make the necessary adjustments.

A Global Navigation Satellite System (GLONASS) is being deployed today, similar to US GPS and operating on the same principles. The difference lies in the signal coding and decryption systems and the spatial data processing algorithms. 


\section{Cloud technology capabilities}

The classic approach to business process automation, established in the period 2000-2010, requires that an organization must have a pool of server equipment to provide services for information support and reliable protection of its core processes. Obviously, such infrastructure requires expensive servers and networking equipment, including routers and firewalls for security, as well as client stations for service users and related software. It is also clear that many organizations, especially in the small and medium-sized businesses, cannot afford this approach to information infrastructure.

The trend of the last five years, characterized by the widespread proliferation of cloud services and cloud storage and data processing, opens up new opportunities for automation and maintenance of business processes.

Cloud computing is a model for providing on-demand network access to a pool of configurable computing and information resources, such as data networks, servers, storage, applications and services. This approach provides a lot of convenience for users, shortens the waiting time and access to the resource, makes the user independent in the choice of resources. However, there are a number of new problems. Not all the necessary services will be able to be transferred to the clouds in the coming years.

There are a number of restrictions that you can not get around. Requirement for the width of the data channel, for data protection and encryption, the inability to work in a virtual environment and a hypervisor environment - the list can be continued. That is why a new approach to data organization and work is currently being actively developed, on the basis of which hybrid systems are designed to inform the organization's processes.

In particular, it is proposed to gradually, in the course of modernization, rebuild the existing information infrastructure into infrastructure built on the principle of a private cloud. This allows you to get results in the form of rapid migration between public and private cloud. For example, collaborative, distributed work technologies are in great demand today.

One of the tools for organizing such work is a corporate or educational portal. The MS SharePoint portal allows you to organize distributed work. 
If the infrastructure is built on the principle of a private cloud, it will only require copying virtual machines to a public cloud. In the case of a classic approach to information infrastructure development, a migration project would involve the deployment of new infrastructure and the transfer of old data to a new environment, which is a very time consuming project. This solution can be effectively integrated with your existing organization network. It can be implemented in a hypervisor environment, allowing you to effectively manage the cluster of virtual machines, if necessary, migrate them to the cloud, such as the Windows Azure platform.

Thus, today it is possible to build a hybrid solution - a portal on a corporate server and working applications and data arrays in a private cloud, with the ability to scale into a public cloud.

A hybrid approach to information infrastructure development is an approach whereby some of the resources for which it is appropriate are brought to the public cloud and some of the most critical, business-relevant services remain within the company's information infrastructure. Such an information infrastructure should be built on the principles of a private cloud, using virtualization technologies, to allow for the migration of services, if necessary, in both directions. When using this approach, services should be designed based on the same principles, in order to organize unified approaches to information security.

To ensure the safe operation of a hybrid infrastructure, the following basic rules must be followed:

- control of strict observance of information security policy in the distributed parts of the organization;

- admission to cloud services or hybrid solution by professionals only;

- agreeing on local policies and safeguards at the level of users, network providers and service owners;

- additional local data storage, where possible;

- taking into account the importance of a particular information resource of the enterprise for the business as a whole;

- accounting for new threats when migrating any content to external services.

The private cloud approach to the organization of infrastructure within the company will allow to provide high availability and resiliency of such services, using virtualization technologies. On the one hand, the solution 
remains secure, on the other hand, it becomes effective and scalable. The designed infrastructure becomes distributed, which in its competent organization, reduces the risks for enterprises in case of emergencies.

\section{REFERENCES}

1. Марк Спортак, Френк Паппас и др. Компьютерные сети и сетевые технологии. PlatinumEdition: Пер. сангл. Санкт-Питербург.: ООО «ДиаСофтЮП», 2005. 720 с.

2. Фролов А.В., Фролов Г.В. Глобальные сети компьютеров: Практическое введение в Internet, E-mail, FTP, WWW и HTML, программирование для WindiwsSockets. Москва: Диалог. Москва: МИФИ, 1996. 283 c.

\section{Information about the author:} Kyselov V. B.

Doctor of Technical Sciences, Professor, Director of the Institute of Municipal Administration and Urban Economics of the V. I. Vernadsky Taurida National University 